This work has been submitted to NECTAR, the Northampton Electronic Collection of Theses and Research.

\title{
Article
}

Title: Interaction and effectiveness of corporate e-learning programmes

Creators: Padilla Rodriguez, B. C. and Armellini, A.

DOI: $10.1080 / 13678868.2013 .803753$

Example citation: Padilla Rodriguez, B. C. and Armellini, A. (2013) Interaction and effectiveness of corporate e-learning programmes. Human Resource Development International. 16(4), pp. 480-489. 1367-8868.

It is advisable to refer to the publisher's version if you intend to cite from this work.

Version: Accepted version

Note: This is an Accepted Manuscript of an article published by Taylor \& Francis in Human Resource Development International on 18 Jun 2013, available online: http://www.tandfonline.com/10.1080/13678868.2013.803753.

http://nectar.northampton.ac.uk/5469/ 


\title{
Perspectives
}

\section{Interaction and Effectiveness of Corporate E-learning Programmes}

\author{
Brenda Cecilia Padilla Rodriguez ${ }^{\mathrm{a}} \&$ Alejandro Armellini ${ }^{\mathrm{b}}$ \\ ${ }^{a}$ Institute of Learning Innovation, University of Leicester, Leicester, United Kingdom \\ ${ }^{\mathrm{b}}$ Institute of Learning and Teaching, University of Northampton, Northampton, United \\ Kingdom
}

\begin{abstract}
This study was conducted in a large Mexican organisation running a virtual corporate university. It aimed to evaluate students' perceptions of three types of interaction (learner-teacher, learner-content and learner-learner) and their views on the effectiveness of online courses in terms of satisfaction, learning and behaviours. Twenty-six employees who had studied at least one online course within the organisation answered an online survey. Four of them were interviewed. Results show that: 1) Learners value their interaction with the content the most. 2) Online learning is generally perceived as an effective method for delivering corporate training. 3) There is no perceived relationship between online interactions and training effectiveness. The findings are limited to the specific context of the participating organisation. Further research into online learning in corporate settings is needed to understand training interactions and changes in job performance.
\end{abstract}

Keywords: online learning; interaction; equivalency; effectiveness; e-learning; Mexico

Interaction is considered crucial in education (e.g., Anderson and Garrison 1998; Miyazoe and Anderson 2010). Studies conducted in schools and universities (e.g., Chang and Smith 2008; Su et al. 2005) have emphasized the importance of social interactions (i.e., between people) to foster learning. In business settings, however, it is not always possible to generate such interactions for learning purposes. This may be due to the lack of focus on successful pedagogical design models (e.g., Macpherson et al. 
2004) or to specific needs, such as who requires which training and when. It is common for organisations to have programmes with limited social interactions (e.g., Welsh et al. 2003). Do these restrictions have an impact on the effectiveness of online corporate training?

\section{Online Interactions}

Educational interactions are reciprocal events with at least two actions and two objects mutually influencing one another (Wagner 1994). Moore (1989) described three main types, which are crucial for success in online courses (Swan 2002):

(1) Learner-content interaction. The provision of materials alone is usually not enough to foster learning, which requires students to actively engage with the content purposefully (Anderson and Garrison 1998). Online course participants tend to rank learner-content interactions highly (Kellogg and Smith 2009; Miyazoe and Anderson 2010; Rhode 2009).

(2) Learner-learner interaction. While some online students appreciate opportunities to work and share ideas with their peers (Chang and Smith 2008; Su et al. 2005), others feel that these are tangential (Kellogg and Smith 2009; Rhode 2009).

(3) Learner-teacher interaction. Instructors are regarded as experts in the subject they teach. Thus, communication with them has a high perceived value amongst learners (Anderson 2003; Rhode 2009; Su et al. 2005).

Based on Moore’s (1989) taxonomy, Anderson (2003) developed the interaction equivalency theorem, which establishes that deep, meaningful learning can be supported 
as long as one of three types of interaction (learner-content, learner-learner or learnerteacher) is present at a high level. The other two forms can be offered in a minimal degree, or omitted, without decreasing the quality of learning. For corporations that find it hard to build high levels of all types of interaction into their courses, this thesis, if supported, may be of great help in the design of more efficient training programmes.

Support for the interaction equivalency theorem is mixed so far. A meta-analysis conducted by Bernard and colleagues (2009) found that high and moderate levels of learner-content, learner-learner and learner-teacher interactions result in better academic performance than low levels. On the other hand, students of a self-paced online course considered that learner-teacher or learner-content interactions could not be "diminished or eliminated and compensated by other forms of interaction” (Rhode 2009, 14).

\section{Training Effectiveness}

The interaction equivalency theorem focuses on learning. However, corporate programmes require other indicators to validate their effectiveness. Kirkpatrick (1979) created the most widely used framework for training evaluation (DeRouin et al. 2005). It consists of four steps (also called levels):

(1) Reactions: Satisfaction (Kirkpatrick 1979). Employees tend to have positive reactions towards online training (e.g., Skillsoft 2004), which relates to the intention to take future courses (Long, DuBois and Faley 2008).

(2) Learning: Acquisition of knowledge or skills (Kirkpatrick 1979). Most students at organisations consider that they learn what they need from online training (DeRouin et al. 2005), regardless of their completion of the courses (e.g., Welsh et al. 2003). 
(3) Behaviours: Application of the acquired knowledge in the workplace (Kirkpatrick 1979), also known as knowledge transfer. The literature suggests that e-learning in a corporate setting can improve job performance (e.g., Anger et al. 2006; DeRouin et al. 2005).

(4) Results: Broader, organisational indicators like increased sales, improved quality, higher productivity and reduced costs (Kirkpatrick 1979). While research into this level is scarce, there is some evidence that e-learning can positively influence business results (e.g., Anger et al. 2006; DeRouin et al. 2005).

An example can illustrate the application of the four steps: Consider an organisation that delivers a course on sales techniques. The evaluation of training effectiveness would be conducted as follows: (1) Reactions (were participants satisfied with the course?); (2) Learning (did they learn the sales techniques?); (3) Behaviour (are they applying the sales techniques in their workplace?); (4) Results (are sales increasing?). While measurements become more complicated and expensive as the evaluation process advances through the four steps, the resulting information becomes more meaningful (Kirkpatrick 1979).

Online interactions can potentially enhance the effectiveness of courses delivered in organisations in different ways and at different levels. However, the relationship between interactions and effectiveness needs further research. This is the focus of this paper. 


\section{Purpose of this Study}

This study aimed to evaluate students' perceptions of the importance and quality of three different types of interaction (learner-teacher, learner-content and learner-learner) and of the effectiveness (satisfaction, learning and behaviours) of online courses.

The research questions were:

(1) What type of interaction do learners value the most in online training courses?

(2) How effective do learners consider their online training courses to be?

(3) What is the relationship between the quality of interactions and the perceived effectiveness of online training courses?

If there is evidence of a relationship between the quality of interactions and the effectiveness of online training courses, it may indicate that the first thesis of the interaction equivalency theorem (Anderson 2003) can apply in business settings.

\section{Context}

The participating organisation, a large Mexican corporation, is a leading consumer company in Latin America. It has over 150,000 employees. In order to provide personal and professional development opportunities for its human resources, it created a virtual corporate university in 2010. Its Organisational Development Department designs the training programmes using an internally developed learning model based on competences. For each job, each competence has a specific definition and key performance indicators that describe expected behaviours. The courses focus on those 
indicators, and typically include an introduction, topic-related texts and exercises (e.g., questions and quizzes).

In some cases it is a requirement for employees to undergo specific training programmes (for example, to certify them on the use of a software package needed for their job). Staff may also ask to register for a course because they think it could be useful for them (e.g., English language).

Courses are delivered via the SumTotal management system and use different resources and tools, such as online quizzes, reading materials, videos and podcasts. While some participants find opportunities for occasional social interactions with peers and tutors (primarily by telephone and in face-to-face mode), learner-content is the prevailing type of interaction designed into the courses. Courses tend to be short, usually requiring 1-2 hours of online study. Assessment processes vary depending on the objectives. They can include exams and projects in which students have to apply the acquired knowledge in their workplace. Additionally, learners are asked to answer a satisfaction questionnaire for every course they take.

\section{Method}

\section{Participants}

A purposive sample of fifty online students was agreed between the researchers and the organisation. The response rate was of 52\%, with 26 people (13 men and 13 women) agreeing to participate in this study. This is consistent with organisational research average response rates (Baruch and Holtom 2008). 
Participants' ages ranged from 24 to 53 years, with a mean of 35 . All of them had higher education experience (18 had a Bachelor's degree; 7 had a Master’s degree; and 1 had incomplete undergraduate studies). They worked in different departments including Operations, Human Resources and Marketing. Twenty-one of them had been working at the company for 3.5 years or more. Participants' tenure ranged from 1 month to 30 years and 7 months.

Twenty-two respondents considered themselves skilled or very skilled with the use of technology. No one considered themselves unskilled. The majority (20) had participated in at least two online training programmes within the organisation, and six respondents had studied more than ten. Less than half (10) had taken an external webbased course, with nine out of these ten rating it as good or excellent.

\section{Instruments}

\section{Online survey}

Surveys are one of the most frequently used data collection tools in business settings. They provide insight into individual perceptions and tendencies within groups (Baruch and Holtom 2008). When applied online, they represent a low-cost, time-saving method.

An online survey was designed to obtain quantitative data from participants. It had an informed consent statement at the beginning and space for comments at the end. The instrument comprised three main areas: 1) learner's profile, 2) perceptions of interactions and 3) perceptions of training effectiveness. In the first section, participants provided general demographic data (summarised above). In the second, they rated the importance and quality of different types of interaction (learner-content, learner-learner 
and learner-teacher). In the third, they evaluated different levels of training effectiveness (satisfaction, learning and behaviours).

Prior to its administration, four academics with experience in e-learning research (two from the United Kingdom and two from Mexico) evaluated the online survey to help establish face and content validity. A version of the survey in Spanish was produced. Three potential participants checked its clarity. Modifications were made where necessary.

\section{Interview guides}

The researchers used interview guides to conduct semi-structured interviews, each lasting approximately 30 minutes. This instrument was chosen because it allows participants' experiences, thoughts and feelings to guide the interview, while staying within the framework of the research aim (O’Donnell and Tobbell 2007).

Four interviews were conducted with learners. They aimed to gain a deeper insight into students' perceptions of interactions and training effectiveness, as well as the relationship between the two. They attempted to clarify and fill the gaps identified through the survey findings. Participants rated the importance of different types of interaction (learner-content, learner-learner and learner-teacher) and evaluated different levels of training effectiveness (satisfaction, learning and behaviours). They had opportunities to provide reasons for their answers.

Additional questions directly explored the first thesis of Anderson’s (2003) interaction equivalency theorem. The researchers examined students' perceptions of training effectiveness if different types of interaction were present at high or low levels. For example, if a respondent argued that interaction with the content was the most important and interaction with other students was the least important type, the 
researchers subsequently asked whether a course with high levels of learner-learner interaction and low levels of learner-content interaction would change the educational experience, and if so, how.

\section{Procedure}

The online survey was available to 50 potential respondents for three weeks. Twenty-six employees responded. This response rate (52\%) is consistent with other studies using data from individuals in organisations (Baruch and Holtom 2008).

Answers were stored on the survey software web server. Results were downloaded in Excel format and imported into the Statistical Package for Social Sciences (SPSS). Frequencies and measures of central distribution were obtained. Spearman correlations and chi-square tests were calculated to establish the relationship between the different types of interaction and the levels of training effectiveness. Two coders analysed the answers of open-ended questions independently, with an overall agreement of $83.3 \%$. A third coder resolved disagreements.

Interviews were conducted via Skype with four employees, all of whom had completed the online survey. The interviews were recorded, with their agreement. At the beginning of each interview, information about the study was given and anonymity was assured. This resulted in rich narrative descriptions of learners' perceptions of interaction and training effectiveness.

Two coders analysed the interview transcripts independently. The themes for categorization were the different types of interaction (learner-content, learner-learner and learner-teacher) and the different levels of training effectiveness (satisfaction, learning and behaviours). The coders had an overall agreement rate of 89.5\%.

Results of the survey and the interviews were compared and contrasted. 


\section{Results}

Results were grouped in three major areas that correspond to the research questions (RQs) of this study.

\section{RQ 1: What type of interaction do learners value the most in online training courses?}

The online survey suggested that learner-content interaction was the most valued type of interaction, with $100 \%$ of respondents considering it the most important element in a web-based programme. It also had the highest perceived quality, with $100 \%$ of participating students stating that the content of their online courses stimulated their thinking on the topic.

In the interviews, all participants agreed that learner-content was the most important type of interaction. As one respondent put it, sometimes in online programmes there is no dialogue with peers or with the instructor, so the content is all learners have to work with. Another respondent added that communication with other students was not too important because if lacking, it did not interfere with learning.

While agreeing on its relevance, one student pointed out the limitations of interaction with the content. She explained that although sometimes this form of interaction can provide the learner with feedback (e.g., after an answer to a question), the material in the course "does not reply if you ask something”. She added that people, especially other students, can provide more enriching information by sharing their experiences, in a way that the content cannot. However, she also commented that she had never had an online educational programme with learner-learner interaction and that she was basing her opinion on assumptions. 
Table 1 presents the means and standard deviations of participants’ perceptions of different types of interactions, according to the survey results. Larger numbers refer to higher perceived importance (max. $=3$ ) or quality (max. $=5$ ).

[Insert Table 1 about here]

Social interactions (i.e., between people) were seen as less important than learner-content interaction. The researchers asked interviewees about the interaction opportunities offered in their web-based courses at the organisation. All courses had been designed to include activities and resources that foster learner-content interactions (e.g., reading materials, videos and podcasts followed by exercises). None had built-in communication opportunities with fellow students. There was no access to chats, discussion forums, blogs or wikis. Only one course had an approachable teacher with whom contact was possible weekly by telephone. This highlights the absence of socialisation opportunities in the design and delivery of these online courses.

\section{RQ 2: How effective do learners consider their online training courses to be?}

The answer to this question is based on the first three steps of Kirkpatrick’s (1979) framework of the evaluation of training effectiveness (satisfaction, learning, and behaviours).

\section{Satisfaction}

The majority of survey respondents (69\%; 18/26) reported they were either satisfied or very satisfied with their online courses, and all but one of them (96\%) claimed that they 
would recommend the programme to a colleague. However, 19\% (5/26) of those taking the survey said they were very dissatisfied.

All four interviewed students stated that they were satisfied with their programmes. They all considered that the training objective had been fulfilled. Two added that the material was interesting and entertaining. One considered that while the goal was achieved, the course was boring. She compared it to a PowerPoint presentation in black, white and grey. Although the right information was presented and she was satisfied with it, the programme lacked dynamism and fun. Another one described her programme in a similar way: "Well, it is an online course but without an instructor or other participants; that is, I take it on my own, on my computer. I see it, and that's it. Like slides I go through...”.

Eleven respondents included a comment in the survey. Eight of them made positive remarks about the online course while the remaining three were neutral. Interestingly, some participants stated their dissatisfaction in the survey but provided positive comments on their courses during the interviews. For instance:

- $\quad$ "The e-learning courses I have taken are exceptional and have great content. [...] They have been useful for my personal and professional development.” - "I would like to keep participating in this type of virtual courses.”

- "Thank you for these courses. They are really useful, and they help me improve my performance.”

- “[...] Congratulations on giving employees the opportunity of seeing, feeling and living this unique experience...” 
Interviewed learners explained this inconsistency in different ways. One indicated that students might not want to get into trouble by expressing their dissatisfaction, so they balanced things out by also including positive comments. Others argued that students generally feel very dissatisfied with their online programmes, but do recognize their value. A third reason for this inconsistency was that some believe the content is adequate, but problems with the design or the technology cause dissatisfaction.

\section{Learning}

Only 69\% (18/26) of survey respondents had completed their online course. When asked if they had learned what they needed to learn, 46\% (12/26) said yes; 39\% (10/26), almost; and 15\% (4/26), replied not yet. No one reported to have 'not learned'.

\section{Behaviours}

Most participants (81\%; 21/26) reported having shared what they had learned with their co-workers. Only $43 \%$ of them (9/21) gave a concrete example of how they had done it; for example, "I told a colleague how to access the system to obtain some information". The rest either gave a general, ambiguous example (38\%; 8/21), like “organizing my work”, or did not answer.

The majority of respondents (89\%; 23/26) stated they had been able to apply the learned knowledge in their workplace. However, only 57\% of students (13/23) gave a concrete example of how they had applied the knowledge; for example, "I learned how to use my employee card to open doors; if I am coming in with someone else, both of us 
have to swipe our cards”. The rest either provided a vague example (35\%; 8/23), like “managing personnel”, or failed to answer.

Table 2 summarises the results of the different evaluation steps.

[Insert Table 2 about here]

\section{RQ3: What is the relationship between the perceived quality of interactions and the perceived effectiveness of online training courses?}

In the interviews it became clear that students think learning is closely related to interaction with the content: "The topic and the questions develop from this [interaction with the content]. The conversation you can have with the teacher or with other participants emerges from this”. However, survey data provided no evidence of any statistically significant relationship between the perceived quality of interactions and effectiveness of online training courses (satisfaction, learning and behaviours).

Considering Anderson’s (2003) thesis (meaningful learning can be supported as long as one of three types of interaction is present at a high level; the other two forms can be offered in a minimal degree without decreasing the quality of learning), the researchers asked interviewees if their educational experience would change if various types of interaction were present at different levels, and if so, how. No matter how the question was worded, all respondents agreed that learner-content, learner-learner and learner-teacher interactions are not equivalent and thus, not interchangeable.

Participants did not consider that high levels of one form of interaction would necessarily compensate for low levels of another. One student said that learner-learner interaction was more important for skill-focused courses than for knowledge-based programmes. Another indicated that "it all depends on what you want to learn”. 
The researchers expected to find a relationship between the perceived quality of interactions and different indicators of the effectiveness of online training programmes. However, the survey provided no statistically significant evidence of this.

\section{Discussion}

In line with other reports (e.g., Kellogg and Smith 2009; Miyazoe and Anderson 2010; Rhode 2009), respondents in this study ranked learner-content interaction highly. However, online courses at the participating organisation seem to offer limited social interaction opportunities, which is common in business settings (e.g., Welsh et al. 2003). This absence may have influenced the results: Participants had little to compare learner-content interaction with.

The four interviewed students stated that they only had online interactions with the content in their courses. Some participants may have answered questions about learner-learner and learner-teacher interactions based on their beliefs or their experiences in external courses, and not on their actual training programmes within the organisation. Further research should aim to obtain concrete information about social interactions available in online courses in business settings.

The perceived effectiveness of the online courses was consistent with the findings of previous studies. Most participants were satisfied with their programmes (Skillsoft 2004) and considered they were able to apply the new knowledge in their workplace (Anger et al. 2006; DeRouin et al. 2005). Interestingly, although most students claimed to have shared and applied new knowledge, half of them did not provide a concrete example of how they had achieved this. Possible explanations include participants' inability to clearly explain what they had done and their possible 
wish to avoid being questioned further, by claiming to have taken full advantage of the courses even if this was not the case.

Finally, the researchers did not find a relationship between online interactions and training effectiveness. As in Rhode’s (2009) study, participants did not consider that high levels of one type of interaction would necessarily compensate for low levels of another, which negates the thesis of the interaction equivalency theorem (Anderson 2003). On the contrary, learner-content interaction should remain high to keep effectiveness high, irrespective of the levels of the other two types of interaction.

\section{Conclusions}

The three key conclusions are:

(1) Learners value their interaction with the content the most. As might be expected, engaging content (including resources and activities) leads to positive student reactions towards the course. Other forms of interaction were not prominent in the courses that respondents had taken before.

(2) Online learning is perceived as a suitable, effective option for delivering training in the organisation. Most participants were satisfied with their courses, considered they had at least partially learned what they needed and reported applying the acquired knowledge.

(3) There is no perceived relationship between online interactions and training effectiveness. There is no statistically significant relationship between the perceived quality of different types of interactions (learner-content, learnerlearner and learner-teacher) and different indicators of the effectiveness of 
online programmes (satisfaction, learning and behaviours). The data provided no support for Anderson's (2003) thesis of the interaction equivalency theorem.

The findings of this study are limited to the particular context of the participating organisation in Mexico, which offers courses with extensive learnercontent but few social interactions. A second limitation relates to the participants involved in the study. While purposive sampling focuses on people who are relevant to the research questions, it is a non-probabilistic approach. A larger, probabilistic sample could allow reliable generalizations to the population. Further research is needed to understand training interactions and changes in job performance. Looking into corporate online learning settings that foster learner-learner and learner-teacher interactions may yield a deeper understanding on this topic.

\section{References}

Anderson, T. 2003. Getting the mix right again: An updated and theoretical rationale for interaction. International Review of Research in Open and Distance Learning 4, no.2. http://www.irrodl.org/index.php/irrodl/article/view/149/230

Anderson, T., and D. R. Garrison. 1998. Learning in a networked world: New roles and responsibilities. In Distance learners in higher education, ed. C. Gibson, 97-112. Madison, WI: Atwood Publishing.

Anger, W., J. Stupfel, T. Ammerman, A. Tamulinas, T. Bodner, and D. Rohlman 2006. The suitability of computer-based training for workers with limited formal education: a case study from the US agricultural sector. International Journal of Training \& Development 10, no.4: 269-84. 
Baruch, Y. and B. C. Holtom. 2008. Survey response rate levels and trends in organisational research. Human Relations 61, no.8: 1139-1160.

Bernard, R. M., P. C. Abrami, E. Borokhovski, C. A. Wade, R. M. Tamim, M. A. Surkes, and E. C. Bethel. 2009. A meta-analysis of three types of interaction treatments in distance education. Review of Educational Research 79, no.3: 1243-1289.

Chang, S.- H. H. and R. A. Smith. 2008. Effectiveness of personal interaction in a learner-centered paradigm distance education class based on student satisfaction. Journal of Research on Technology in Education 40, no.4: 407-426.

DeRouin, R. E., B. A. Fritzsche, and E. Salas. 2005. E-learning in organisations. Journal of Management 31, no.6: 920-940.

Kellogg, D. L. and M. A. Smith. 2009. Student-to-student interaction revisited: A case study of working adult business student in online courses. Decision Sciences Journal of Innovative Education 7, no.2: 433-456.

Kirkpatrick, D. 1979. Techniques for evaluating training programs. Training and Development Journal 33, no.6: 78-92.

Kirkpatrick, J. D. and W. K. Kirkpatrick. 2010. Training on trial: How workplace learning must reinvent itself to remain relevant. New York, NY: AMACOM.

Long, L. K., C. Z. DuBois, and R. H. Faley. 2008. Online training: The value of capturing trainee reactions. Journal of Workplace Learning 20, no.1: 21-37.

Macpherson, A., M. Elliot, I. Harris, and G. Homan. 2004. E-learning: Reflections and evaluation of corporate programmes. Human Resource Development International 7, no.3: 295-313. 
Miyazoe, T. and T. Anderson. 2010. Empirical research on learners’ perceptions:

Interaction equivalency theorem in blended learning. European Journal of Open, Distance and E-Learning. http://www.eurodl.org/?article=397

Moore, M. G. 1989. Three types of interaction. The American Journal of Distance Education 3, no.2: 1-6.

O’Donnell, V. L. and J. Tobbell. 2007. The transition of adult students to higher education: Legitimate peripheral participation in a community of practice? Adult Education Quarterly 57, no.4: 312-328.

Rhode, J. F. 2009. Interaction equivalency in self-paced online learning environments: An exploration of learner preferences. International Review of Research in Open and Distance Learning 10, no.1. http://www.irrodl.org/index.php/irrodl/article/viewArticle/603/1178

Skillsoft. 2004. EMEA e-learning benchmark survey: The users’ perspective. http://www.oktopusz.hu/domain9/files/modules/module15/365BAE FCF22C27D.pdf

Su, B., C.J. Bonk, R.J. Magjuka, X. Liu, and S. Lee. 2005. The importance of interaction in web-based education: A program-level case study of online MBA courses. Journal of Interactive Online Learning 4, no.1: 1-19.

Swan, K. 2002. Building learning communities in online courses: The importance of interaction, Education, Communication \& Information 2, no.1, 23-49.

Wagner, E. D. 1994. In support of a functional definition of interaction. The American Journal of Distance Education, 8, no.2: 6-26.

Welsh, E. T., C. R. Wanberg, K. G. Brown, and M. J. Simmering. 2003. E-learning: Emerging uses, empirical results and future directions. International Journal of Training and Development 7, no.4: 245-258. 